\title{
A ALIANÇA BÍBLICA UNIVERSITÁRIA E A MISSÃO INTEGRAL NO BRASIL
}

\author{
Alfredo dos Santos Oliva ${ }^{1}$
}

\section{RESUMO}

O discurso (conceito teológico elaborado e pronunciado espontânea ou formalmente) está atrelado a uma série de práticas que são concretizadas através de instituições ou ações espontâneas de pessoas. O conceito teológico de Missão Integral circula em solo brasileiro através de pessoas, movimentos e instituições, sendo um desses movimentos a Aliança Bíblica Universitária do Brasil (ABUB).

\section{PALAVRAS-CHAVE}

Discurso teológico, missão integral, sociedade brasileira.

\section{ABSTRACT}

Discourse (theological concept created and spoken in a spontaneous or a formal way) is linked to practices that are performed by institutions or individuals spontaneously. The concept of Integral Mission is supported by people, movements and institutions, and one of these movements is Aliança Bíblica Universitária do Brasil (ABUB).

\section{KEY-WORDS}

Theological discourse, integral mission, Brazilian society.

\footnotetext{
${ }^{1}$ Alfredo dos Santos Oliva, doutor em História pela UNESP (Campus de Assis - SP), é professor Adjunto do Departamento de História da Universidade Estadual de Londrina - UEL.
} 
Todo discurso (conceito teológico elaborado e pronunciado espontânea ou formalmente) está atrelado a uma série de práticas que são concretizadas através de instituições ou ações espontâneas de pessoas. A missão integral não foge a este princípio. Embora seja um conceito que ainda não recebeu o devido tratamento sistemático, há bastante tempo circula em solo brasileiro através de pessoas, movimentos e instituições. Um desses movimentos é a Aliança Bíblica Universitária do Brasil (ABUB). Desta agremiação de estudantes e profissionais e de sua relação com o conceito de missão integral no Brasil é que este texto se ocupa.

A trajetória para levar adiante o propósito acima colocado começa por uma busca da identidade teológica e institucional da ABUB. Procuro responder a questões como: Que é a ABUB? Como está estruturada institucionalmente? Quais os seus objetivos? Que concepções teológicas endossa e procura difundir? Que sociabilidades procura construir?

No segundo tópico deste artigo passo a me ocupar especificamente da concepção de missão integral da ABUB. Começo conceituando missão integral, de uma forma geral, para depois colocar o foco sobre como esta elabora, compreende ou difunde o conceito em seu meio.

O terceiro passo será analisar as estratégias que a ABUB utilizou ou tem utilizado para difundir sua concepção de missão integral. Alguns veículos de comunicação e socialização de idéias serão analisados, como sua Editora, a organização de congressos e treinamentos e seu site na rede mundial de computadores.

\section{A identidade da Aliança Bíblica Universitária do Brasil}

A ABUB é "essencialmente um movimento missionário, interdenominacional, eclesiástico e confessional, liderado pelos seus próprios participantes". Os estudantes (do ensino médio e universitários) bem como os profissionais se "organizam em grupos por cidades, filiandose assim ao movimento nacional da ABUB, respectivamente em seus grupos de ABS (Aliança Bíblica Secundarista), ABU (Aliança Bíblica Universitária) e ABP (Aliança Bíblica de Profissionais)". (Aliança Bíblica Universitária do Brasil, 2011). 
Além disso, a ABUB está ligada a um movimento internacional de estudantes evangélicos. Esta afiliação é reconhecida pela liderança da agremiação estudantil e profissional brasileira como um dos elementos fundamentais de constituição de sua identidade teológica: "Há um conjunto de bases de fé que compõem o núcleo da identidade evangélica dos participantes. Essas bases de fé são conforme as da Comunidade Internacional de Estudantes Evangélicos (CIEE), da qual a ABUB faz parte como membro filiado". (Aliança Bíblica Universitária do Brasil, 2011).

A identidade teológica do movimento parece estar em perfeita sintonia com o que se poderia denominar de evangélico no Brasil ou evangelical na Europa. Esta forma de auto-identificação doutrinária pode ser evidenciada pela afirmação de dogmas bastante tradicionais neste meio por parte da ABUB em sua base de fé, como autoridade das Escrituras, Jesus Cristo como único mediador entre o ser humano e Deus, bem como sua ressurreição e segunda vinda. A ABUB professa acreditar nos seguintes aspectos:

a) A existência de um só Deus Pai, Filho e Espírito Santo, um em essência e trino em pessoas; b) A soberania de Deus na criação, revelação, redenção e juízo final; c) A inspiração divina, veracidade e integridade da bíblia, tal como foi revelado originalmente e sua suprema autoridade em assuntos de fé e conduta; d) A pecaminosidade universal e a culpabilidade de todos os homens, desde a queda de Adão, pondo-nos sob a ira da condenação de Deus; e) A redenção da culpabilidade, pena, domínio e corrupção do pecado, somente por meio da morte expiatória do Senhor Jesus Cristo o filho encarnado de Deus, nosso representante substituto; f) A ressurreição corporal do Senhor Jesus Cristo e sua ascensão à direita de Deus Pai; g) Missão pessoal do Espírito Santo para o arrependimento, a regeneração e a santificação dos crentes; h) A justificação do pecado somente pela graça de Deus, por meio da fé em Jesus Cristo; i) A intervenção de Jesus Cristo como único intercessor entre Deus e os homens; j) A única igreja santa e universal, que é o corpo de Cristo, à qual todos os crentes verdadeiros pertencem e que, na terra, se manifesta nas congregações locais; k) A segurança da segunda vin- 
da de cristo em corpo glorificado e a consumação de seu reino nesta manifestação; 1) A ressurreição dos mortos, a vida eterna dos salvos e a condenação eterna dos injustos. (Aliança Bíblica Universitária do Brasil, 2011).

Para levar adiante sua missão, desde uma perspectiva evangélica, a ABUB se estrutura a partir de grupos dirigidos por estudantes e profissionais espalhados por todo território nacional. Principalmente os estudantes são assessorados por ex-abeuenses e profissionais remunerados:

Atualmente a ABUB possui grupos em todos os Estados brasileiros, atingindo mais de 100 cidades. Como forma de suporte ao universitário, contamos com uma estrutura de assessoria aos Grupos. Os assessores geralmente são profissionais ex-abeuenses, pastores ou seminaristas, que dedicam alguns anos da sua vida à obra, ajudando no treinamento local e no discipulado de líderes. AABUB possui 10 assessores remunerados, muitos em parceria com igrejas locais, e mais de 150 assessores auxiliares que oferecem trabalho voluntário. (Aliança Bíblica Universitária do Brasil, 2011).

Para organizar seu trabalho a liderança da ABUB dividiu o país em seis regiões:

[1] ABU Região Norte: Acre; Amapá; Amazonas; Maranhão; Pará; Rondônia; Roraima; [2] ABU Região Nordeste: Alagoas; Bahia; Ceará; Paraíba; Pernambuco; Piauí; Rio Grande do Norte; Sergipe [3] ABU Região Centro-Oeste: Distrito Federal, Goiás, Mato Grosso, Minas Gerais, Tocantins; [4] ABU Região Leste: Espírito Santo e Rio de Janeiro; [5] ABU Região São Paulo: Mato Grosso do Sul e São Paulo; [6] ABU Região Sul: Paraná, Santa Catarina e Rio Grande do Sul. (Aliança Bíblica Universitária do Brasil, 2011).

A filosofia de trabalho da ABUB se baseia em dois princípios, um de caráter doutrinário e outro estrutural/prático. $\mathrm{O}$ movimento de estudantes e profissionais se baseia teologicamente na centralidade da 
pessoa de Jesus Cristo e estrategicamente na ação evangelizadora de estudantes pelos próprios estudantes.

A ABUB é um movimento que tem filosofia CRISTOCÊNTRICA e ESTUDANTECÊNTRICA. Já que a filosofia da ABUB é baseada no estudante, logo os objetivos só poderão ser cumpridos se houver iniciativa e responsabilidade do estudante. $\mathrm{O}$ estudante secundarista/universitário é o melhor evangelista, pois está no meio estudantil e entende melhor os problemas e a linguagem. A iniciativa estudantil evita o paternalismo do obreiro ou assessor auxiliar. Sem a responsabilidade estudantil o trabalho da ABUB é impossível. Responsabilidade que é conseqüência de uma vida cristã autêntica e de amor pela obra e que envolve: assiduidade; vida prática; amor pela obra; e doação financeira. (Aliança Bíblica Universitária do Brasil, 2011).

\section{A concepção da Aliança Bíblica Universitária do Brasil de missão integral}

Antes mesmo de analisar o adjetivo integral, que busca caracterizar um certo modo de fazer missão, é preciso conceituar o que entendo por este substantivo. Vou tomar como a base a definição de David Bosch para quem a palavra missão deve ser compreendida de forma distinta de seu plural, missões:

Temos de distinguir entre missão (no singular) e missões (no plural). O primeiro conceito designa primordialmente a missio Dei (missão de Deus), isto é, a auto-revelação de Deus como Aquele que ama o mundo, o envolvimento de Deus no e com o mundo, a natureza e atividade de Deus, que compreende tanto a igreja quanto o mundo, e das quais a igreja tem o privilégio de participar. Missio Dei enuncia a boa nova de que Deus é um Deus-para as/pelas-pessoas. Missões (as missiones eclesiae, os empreendimentos missionários da igreja) designa formas particulares, relacionadas com tempos, lugares ou necessidades específicos, de participação na missio Dei (Bosch, 2002, p. 28). 
O fato de Deus ter enviado seu Filho Amado ao mundo por amor e solidariedade para com o gênero humano (missão de Deus), exige uma resposta de sua igreja de também agir com o mesmo amor e solidariedade para com a humanidade. Estas ações da igreja precisam ser adequadas ao tempo e ao espaço que tem ocupado no mundo contemporâneo, o que significa que ela deve se preocupar em contextualizar cultural e socialmente suas formas de ação (missões).

Concebida da forma como foi exposta acima, missão é um modo de ação que possui duas dimensões, uma de caráter positivo e outra de cunho negativo. A realização da missão implica em um sim de Deus ao mundo, expresso através sua de solidariedade para com o sofrimento e a desesperança humanos, bem como um não de Deus, expresso de forma conflitiva com os valores e as ações do mundo que são contrários ao seu reinado (Bosch, 2002, pp. 28-29). O que significa que a igreja deve agir para difundir o reinado de Deus sobre o gênero humano anunciando e vivenciando amor e solidariedade, como deve também exercer seu papel profético e denunciar todas as formas de opressão e injustiça que ofuscam o brilho da vida, humana e não-humana.

Uma vez que a missão da igreja desemboca sempre em um processo de contextualização de sua forma de ação no mundo, acho que seria bastante útil qualificar esta missão a partir do adjetivo usado, sobretudo, por missiólogos evangélicos latino-americanos. Para lembrar as igrejas que a sua missão não deve optar por um dos pólos opostos, salvação pessoal/espiritual ou libertação social/econômica, os missiólogos latino-americanos têm usado o qualificativo integral para a missão. Vou procurar detalhar um pouco mais a expressão missão integral a seguir.

A expressão missão integral é utilizada sempre de modo a propor a superação de dualismos. René Padilla, em artigo clássico sobre o assunto de título homônimo, utiliza os termos para se referir à superação da dualidade crescimento quantitativo versus crescimento qualitativo:

É possível usar as estatísticas de crescimento das igrejas para pintar um quadro luminoso da igreja nos últimos anos. Isto é, com efeito, o que se tem feito em círculos onde o crescimento quantitativo da 
igreja é considerado como "a tarefa principal" da missão. O quadro será mais sóbrio se juntamente com os avanços numéricos forem colocados os problemas que afetam a igreja e que colocam em dúvida o futuro do cristianismo em certas regiões do mundo. Nesta perspectiva, o maior desafio que a igreja enfrenta é o desafio de uma missão integral. (Padilla, 1992, p. 139).

O mesmo autor utiliza a expressão com o intuito de superar o dualismo necessidades espirituais versus necessidades materiais. A cidade contemporânea é o símbolo de uma desumanização que afeta a vida humana como um todo, logo as ações da igreja devem estar voltadas para a revigoração destas vidas na sua integralidade:

A missão urbana, portanto, é uma prioridade em todas as partes. Lá, na cidade, com todo seu poder desumanizante, vê-se a necessidade de um evangelho com poder para transformar a totalidade da vida. Num mundo que que está se urbanizando rapidamente, a cidade é, sem dúvida, o símbolo do desafio que a evangelização e o discipulado colocam para a igreja. (Padilla, 1992, p. 142).

A missão integral da igreja tem como horizonte de sua ação o Reino de Deus. O Reino ainda não se encontra em sua plenitude no mundo contemporâneo, mas isto não é motivo para se negar que seus sinais não estejam já entre nós. Os sinais do Reino foram semeados por Nosso Senhor Jesus Cristo, encontrando nele sua expressão privilegiada, mas não se esgotando em suas ações. A missão integral da igreja deve ser concretizada tendo Jesus como modelo de manifestação dos valores do Reino e com vistas à superação do dualismo pregação conversionista versus serviço social amoroso:

Já que o Reino foi inaugurado por Jesus, não é possível entender corretamente a missão da igreja independente da presença do Reino. A missão da igreja é uma extensão da missão de Jesus. É a manifestação, ainda que não completa, do Reino de Deus tanto por meio da proclamação como por meio da ação e do serviço social. [...] Como comunidade do reino, a igreja confessa e proclama ao Senhor Jesus 
Cristo. Ela também realiza boas obras que Deus preparou de antemão para que as faça, para o que Deus a criou em Jesus Cristo [...] As boas obras, portanto, não são um mero apêndice da missão, mas uma parte integral da manifestação presente do Reino: elas apontam para o Reino que já veio e para o Reino que está porvir. (Padilla, 1992, pp. 202-203).

A ação integral da igreja também se fundamenta em uma concepção antropológica. Uma vez que se considere o ser humano como uma totalidade inseparável que possui dimensões diferentes, a igreja deve ser um meio pelo qual o amor de Deus é expresso a este todo. Mais um dualismo é, desta forma, desarticulado, agora o que vê o corpo como realidade distinta de alma e/ou espírito:

Um ministério integral verdadeiro define a evangelização e a ação social como funcionalmente separadas, mas relacionalmente inseparáveis e necessárias para um ministério integral da igreja. [...] A idéia de ministério integral tem raízes bíblicas profundas. Tanto no Antigo como no Novo Testamento a Bíblia ordena à igreja que ministre à pessoa como um todo. Isto quer dizer que se deve atender tanto às necessidades físicas como às espirituais, que estão inseparavelmente relacionadas, ainda que sejam separadas em termos funcionais. (Yamamori, 1998, pp. 14-15).

O conceito de missão integral da ABUB aparece de forma sutil já na descrição de seus objetivos, que são quatro: “A) Evangelização de estudantes; B) Maturidade do homem integral em Cristo; C) Missão e serviço e D) Assistência”. (Aliança Bíblica Universitária do Brasil, 2011).

Três destes objetivos, quando se observa a explicação que a liderança do movimento dá ao seu conteúdo, evidenciam um compromisso com o que se pode compreeender por missão integral acima analisado. A "maturidade do homem integral em Cristo" implica em:

Desenvolvimento Pessoal - A ABUB tem por filosofia o discipulado um a um como Cristo fez. A VIDA PESSOAL (Intelectual, Espiritual, Psicológica, Física) é importante. Desenvolvimento Co- 
munitário - O cristão maduro tem que influenciar o meio. A ABUB forja cristãos que sejam influentes no meio em que vivem e não alienados. (Aliança Bíblica Universitária do Brasil, 2011).

O objetivo de cumprir sua "missão e serviço" implica em uma atitude profética, a de confronto da igreja com as estruturas sociais que estejam ofuscando a vida humana:

A ABUB tem por objetivo a MISSÃO a partir do estudante, começando no seu âmbito estudantil até os confins do mundo. A ABUB tem por objetivo o serviço na Igreja e no mundo. Ser sal e luz e um verdadeiro profeta na situação atual. A ABUB tem por objetivo incentivar os estudantes a descobrirem sua função na sociedade e na igreja. E que tenham uma verdadeira ética cristã. (Aliança Bíblica Universitária do Brasil, 2011).

O seu objetivo de prestar "assistência" não tem como objeto apenas o estudante secundarista ou universitário nas suas dificuldade e conflitos, mas também à "comunidade - Através de projetos de assistência as comunidades, com serviços úteis. $\mathrm{O}$ amor de Deus deve ser demonstrado aos homens através da prática e discurso". (Aliança Bíblica Universitária do Brasil, 2011).

A ABUB procura manter a coerência entre a teoria (aquilo que crê e professa formalmente) e a prática (vivência destes valores professados) transcendendo a mera atividade de evangelizar ou assistir ao estudante em suas necessidades. A instituição estudantil procura estimular os estudantes a se comprometerem com a totalidade da missão, o que envolve cuidar de questões espirituais tanto quanto de questões materiais, através de próprio exemplo.

A Aliança Bíblica Universitária do Brasil (ABUB) é um movimento missionário interdenominacional sem fins lucrativos de estudantes evangélicos que, por intermédio de núcleos de estudo bíblico, literatura e encontros de treinamento, promove a evangelização e a edificação de secundaristas, universitários e profissionais. Desenvolvemos esse trabalho em mais de 100 cidades em todos os Es- 
tados de nosso País, como também o Projeto Missionário Castelão em Fortaleza (CE), que oferece educação básica gratuita para mais de 500 crianças carentes. (Aliança Bíblica Universitária do Brasil, 2011).

\section{A Aliança Bíblica Universitária do Brasil e a difusão da concepção de missão integral}

Através de seus Congressos, publicações, cursos e treinamentos; bem como através da participação de seus membros em eventos missionários, a ABUB tem contribuído significativamente para a difusão da concepção de missão integral no Brasil. Dois de seus congressos são fundamentais sob esta ótica, o que tematizou "Jesus Cristo: Senhorio, Propósito e Missão" e o que tematizou a "Igreja: Comunidade Missionária". Além da conscientização da missão integral dos seus participantes, esses Congressos tiveram suas idéias difundidas através de livros homônimos publicados pela ABUB, ambos já esgotados, e que ajudaram a moldar a idéia de missão de muitas lideranças evangélicas. Se olharmos para a linha editoral da ABU Editora poderemos perceber o alcance de sua contribuição para a difusão da idéia de missão integral:

Vida Cristã - Livros para discipulado, liderança cristã, aconselhamento e edificação, segundo uma perspectiva bíblica equilibrada. Materiais para Evangelização - Folhetos e livretos ótimos para serem usados na evangelização de pessoas questionadoras. Ideal para estudantes e jovens. Igreja e Sociedade Atual - Temas relevantes à igreja que aceitar o desfio de ser bíblica, contextualizada e relevante para o mundo hoje. Doutrina e Bíblia - Livros importantes para aqueles que buscam o sadio entendimento das doutrinas da Bíblia através de enfoques honestos e atuais. Série: A Bíblia Fala Hoje-A série procura levar a sério o texto bíblico, aplicando-o sempre ao mundo moderno. Recomendado pelos seminários. Evangelização e Apologética - Obras de referência indispensáveis para a defesa da fé, evangelização e compreensão da realidade segundo as Escrituras. Estudo Bíblico Indutivo - Obras de referência para liderar e 
criar um grupo de estudo ou para preparar e dirigir um estudo bíblico. (Aliança Bíblica Universitária do Brasil, 2011).

A Editora da ABUB tem se notabilizado pela amplitude dos temas publicados, que abrangem a quase totalidade das preocupações da missão integral. Pode-se perceber a importância do estudo da Bíblia, tanto em ótica exegética quanto em teológica, presente em duas áreas de publicação: a de "doutrina e Bíblia" e a série de comentários bíblicos expositivos "A Bíblia Fala Hoje". Juntamente com a ênfase no estudo bíblico-teológico, há forte ênfase em material para evangelização em geral e de universitários em particular, especialmente através do estudo bíblico indutivo, marca registrada da estratégia evangelizadora dos abeuenses. Quem faz a missão integral precisa de uma espiritualidade integral. A linha de escritos sobre a "Vida Cristã" tematiza a espiritualidade necessária para a ação missionária no mundo atual, obviamente concentrando seus esforços em ajudar a juventude cristã a ser espiritual em meio aos desafios da vida universitária e profissional.

Duas outras linhas complementam a visão da integralidade: "Igreja e Sociedade Atual", na medida em que discernir o tempo presente é fundamental para se realizar a missão integral; e a série "Evangelização e Apologética", que destaca a importância que a ABUB, como o movimento estudantil internacional, dá ao debate sobre a validade da fé cristã no ambiente intelectual contemporâneo. É aqui, a meu ver, que se encontra a maior contribuição peculiar da ABUB à concepção de missão integral e sua difusão no Brasil: fazer missão exige que sejamos capazes de responder aos desafios que o mundo intelectual apresenta à Igreja Evangélica. É parte integrante da missão "responder qual é a razão da nossa esperança", e a ABUB se esmera em preparar a juventude evangélica para fazê-lo.

É, por outro lado, praticamente impossível relatoriar a importância da ABUB na difusão da concepção de missão integral através da consciência missionária integral de seus participantes e, através deles, a influência que, qual fermento, permeia as Igrejas Evangélicas. Mas este é um dado que deve ser ressaltado: através do ministério e da influência de cada abeuense e ex-abeunse, a concepção de missão integral foi se espalhando pelo território nacional e por entre as várias denominações 
evangélicas. Testemunhas do evangelho, abeuenses também têm sido testemunhas da missão integral para a Igreja no Brasil.

\section{Referências bibliográficas}

ALIANÇA Bíblica Universitária do Brasil. Disponível em: <http:// www.abub.org.br>. Aceso em 20/08/2011.

BAUMAN, Z. Modernidade e ambivalência. Rio de Janeiro: Jorge Zahar, 1999.

BITTENCOURT, J. "Do protestantismo sincrético: um ensaio teológico-pastoral sobre o pentecostalismo brasileiro". In: BEOZZO, J. O.

(Org.). Curso de verão ano VII. São Paulo: Paulus, 1993.

BOSCH, D. Missão transformadora: mudanças no paradigma na teologia da missão. São Leopoldo: Sinodal, 2002.

DOMINGUES, J. M. Sociologia e modernidade. Rio de Janeiro: Civilização Brasileira, 1999.

LEMERT, C. Pós-modernismo não é que você pensa. São Paulo: Loyola, 2000.

LYON, D. Pós-modernidade. São Paulo: Paulus, 1998.

PADILLA, R. Missão integral: ensaios sobre o reino e a igreja. São Paulo: FTL, 1992.

PADILLA, R. (Org.). La iglesia local como agente de transformación: una eclesiología para la misón integral. Buenos Aires: Kairós, 2003.

QUIROZ, P. A. et ali. EI trino Dios y la misión integral. Buenos Aires: Kairós, 2003.

STEUERNAGEL, V. R. (Org.). A missão da igreja: uma visão panorâmica sobre os desafios e propostas para a igreja na antevéspera do terceiro milênio. Belo Horizonte: Missão, 1994.

YAMAMORI, T. et ali. Servindo com os pobres na América Latina: modelos de ministério integral. Londrina: Descoberta, 1998.

WARREN, R. Uma igreja com propósitos. São Paulo: Vida, 1997.

WILLARD, D. A conspiração divina: o verdadeiro sentido do discipulado cristão. São Paulo: Mundo Cristão, 2001. 